\title{
Double jeopardy: the potential for problems when bats interact with breathable roofing membranes in the United Kingdom
}

Article

Published Version

Waring, S. D., Essah, E., Gunnell, K. and Bonser, R. (2013) Double jeopardy: the potential for problems when bats interact with breathable roofing membranes in the United Kingdom. Architecture \& Environment, 1 (1). pp. 1-13. ISSN 2329-2296 doi: https://doi.org/10.12966/ae.5.1.2013 Available at https://centaur.reading.ac.uk/33044/

It is advisable to refer to the publisher's version if you intend to cite from the work. See Guidance on citing.

Published version at: http://manuscript.sciknow.org/uploads/ae/pub/ae_1361785788.pdf

Identification Number/DOI: https://doi.org/10.12966/ae.5.1.2013

<https://doi.org/10.12966/ae.5.1.2013>

Publisher: Sciknow Publications Ltd

Publisher statement: SCIKNOW is a not-for-profit publisher devoted to fostering openly shared critical information, scientific research, and dissemination of knowledge on challenging issues in the global academic community.

All outputs in CentAUR are protected by Intellectual Property Rights law, including copyright law. Copyright and IPR is retained by the creators or other copyright holders. Terms and conditions for use of this material are defined in the End User Agreement. 


\section{www.reading.ac.uk/centaur}

\section{CentAUR}

Central Archive at the University of Reading

Reading's research outputs online 


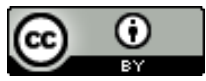

\title{
Double Jeopardy: The Potential for Problems when Bats Interact with Breathable Roofing Membranes in the United Kingdom
}

\author{
S. D. Waring ${ }^{1, *}$, E. A Essah ${ }^{2}$, K. Gunnell ${ }^{3}$, R. H. C Bonser ${ }^{4}$ \\ ${ }^{1}$ Technologies for the Sustainable Built Environment Centre, University of Reading, Reading, UK \\ ${ }^{2}$ School of Construction Management, University of Reading, Reading, UK \\ ${ }^{3}$ Bat Conservation Trust, London, UK \\ ${ }^{4}$ School of Engineering and Design, Brunel University, London, UK \\ *Corresponding author (s.d.waring@pgr.reading.ac.uk)
}

\begin{abstract}
In order to reduce environmental impacts and achieve sustainability, it is important to balance the interactions between the built and natural environment. The construction industry is becoming more aware of ecological concerns and the importance that biodiversity and maintenance ecosystem services has for sustainability. Bats constitute an important component of urban biodiversity and several species in the UK are highly dependent on buildings, making them particularly vulnerable to anthropogenic and environmental changes. Many buildings suitable for use as bat roosts often require re-roofing as they age and traditional bituminous roofing felts are frequently being replaced with breathable roofing membranes (BRMs). In the UK new building regulations and modern materials may substantially reduce the viability of existing roosts, yet at the same time building regulations require that materials be fit for purpose. Reports suggest that both bats and BRMs may experience problems when the two interact. Such information makes it important to understand how house dwelling bats and BRMs may be affected. This paper considers the possible ways in which bats and BRMs may interact, how this could affect existing bat roosts within buildings and the implications for BRM service life predictions and warranties.
\end{abstract}

Keywords -Breathable Roofing Membranes, Bats in Buildings, Material Deterioration, Sustainability, Conservation, Biodiversity

\section{Introduction}

Maintenance of biodiversity and ecological function is a key aspect in achieving sustainability within the built environment. In the UK Government's Strategy for Sustainable Construction (2008), the conservation and enhancement of biodiversity is one of the overarching targets. Due to the increased pressure to reduce environmental impacts, the construction industry has had to become more sensitive to ecological concerns. Combined with the UK Government's broad aim that planning, construction, development and regeneration should have minimal impacts on biodiversity and enhance it wherever possible (Office of the Deputy
Prime Minister, 2005), it has become increasingly important to balance ecological and anthropological interactions within urban areas.

Bats constitute an important component of urban biodiversity and several bat species are highly dependent on buildings, making them particularly vulnerable to anthropogenic and environmental changes. Many buildings suitable for use as bat roosts often require re-roofing as they age. During re-roofing traditional bituminous roofing felts are often replaced with modern membranes, which are designed to reduce the risk of condensation.

New methods and materials are constantly being introduced into the building industry, sometimes in an effort to meet sustainability targets. In the past decade use of non-woven textiles within the roofing industry has seen a 
significant rise, mainly through the production of breathable roofing membranes (BRMs) which are being used more regularly to help meet government guidelines on energy efficiency and sustainability. Until around 10years ago bituminous felt (as described in British Standard BS747:2000) was the roofing underlay specified on most projects. However, over the past decade BRMs have become widely available, with over 60 brands on sale in the UK alone.

Since the introduction of BRMs into roofs where bats roost, there have been reports of problems (see Table 1 of collated reports). These range from deterioration of membranes and entanglement of bats, to microclimate changes within the roof void affecting roost viability (Waring et al., 2012). Although some research has independently considered the effect of BRMs on moisture transport within roof spaces (Chris Sanders, 2006; Essah et al., 2009; Sanders, 2006) and the needs of bats in roost sites (Bartonička and Řehák, 2007; Entwistle et al., 1997; Moussy, 2011; Simon et al., 2004), no work has been carried out to determine what happens when bats and BRMs interact, and the implications this may have for both bat conservation and the service life of BRMs.

\section{Common Structure of UK Roofs}

The traditional pitched roof found on most domestic buildings in the UK consists of a framework of structural elements, usually timber, including rafters and purlins which provide support to the underlay (or boarded sarking which is standard practice in Scotland). Over this tiling batons are nailed to provide support for a fixing point for a layer of weatherproof slates or tiles (Stirling, 2002). For the purpose of this review we will focus on practices that use flexible sheet underlays and not rigid sarking boards.

\subsection{Underlays}

Roofing underlay is principally a thin sheet of material laid over the rafters which serves a number of purposes. Primarily they limit wind penetration into the roof space lessening the risk of slates/tiles being lifted. Secondly they provide an additional barrier to the ingress of dust and wind driven rain/snow, thus ensuring that any moisture that enters the batten void is removed via the external roof drainage system (Garrand, 2008; Goss, 2007; Lounis et al., 1999). More recently underlays have been developed to help reduce the risk of condensation forming within the roof void.

\subsection{Risk of Condensation}

Moisture is regularly produced in buildings from a variety of sources; drying out of materials, vapour exhaled in the breath of occupants and domestic appliances. The heat and moisture generated from such activities can raise the temperature and humidity above the ambient conditions outside the building (Chris Sanders, 2006). This can then lead to moisture moving through the buildings fabric via a combination of conduction, diffusion and convection (Sanders, 2006; Williams, 2008) (see Fig. 1).

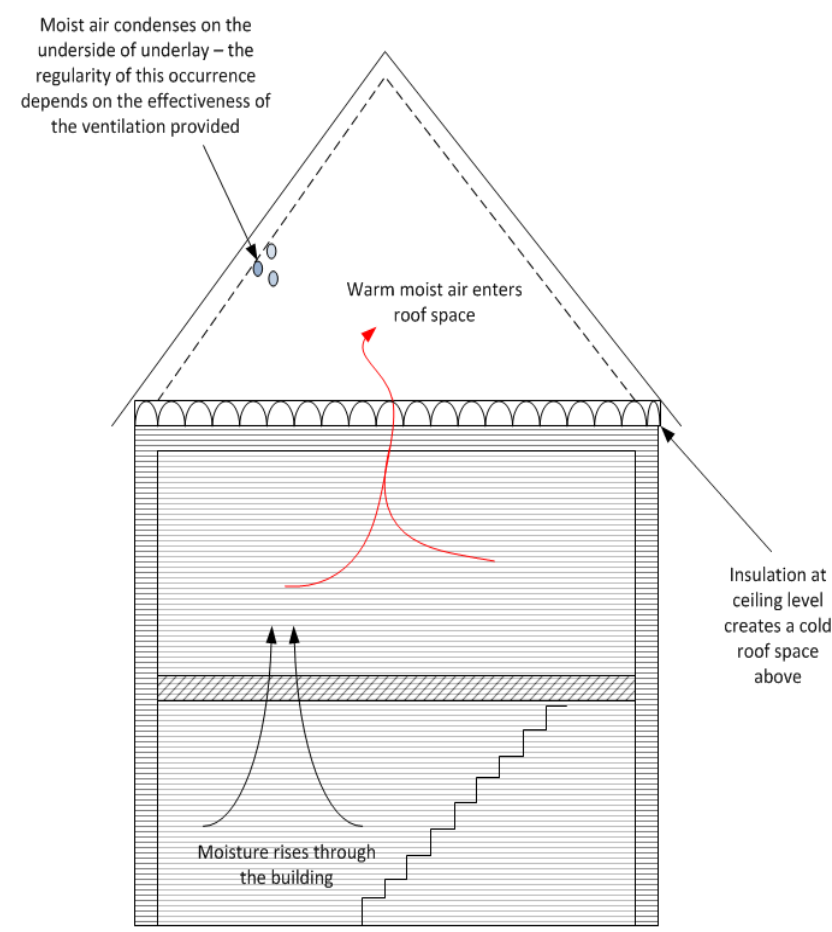

Fig.1. Formation of condensation in a pitched roof with insulation at ceiling level

Pitched roofs have traditionally been insulated at ceiling level, resulting in a cold roof space, hence the term 'cold' pitched roof. Cold pitched roofs, which constitute around $80 \%$ of domestic roofs in the UK (Essah et al., 2009), have insulation on the horizontal ceiling with an accessible cold loft space above. This design makes them intrinsically vulnerable to the formation of condensation on the underlay.

In recent years the risk of condensation has increased as houses have become more energy efficient, with better insulation and increasing air tightness. Higher levels of insulation at ceiling level result in colder roof voids, making the roof space vulnerable to the accumulation of moisture. Moisture saturated air coming into contact with cold surfaces in these roof voids will form condensation (CRC, 2001; Williams, 2008). Sometimes prolonged exposure to condensation will result in deterioration of the roof elements (Stirling, 2002). The use of BRMs in this instance becomes more significant to help reduce the accumulation of moisture and hence protect the fabric of the building (Essah et al., 2009).

When designing a roof architects must take several functions into account; including protecting the building from wind and rain and the prevention of condensation 
(Harrison et al., 2009). Therefore roofing systems must be capable of preventing the ingress of liquid water but allowing water vapour to escape to the external air (Garrand, 2008). One way in which the construction industry has tried to reduce condensation formation and prevent the associated problems, is through the introduction of BRMs. This is because BRMs are designed to facilitate moisture transport from the roof void across the total roof area.

\subsection{Breathable Roofing Membranes}

Breathable membranes have been used in construction throughout Europe since the 1970s; however, they have only more recently become common place in the UK.

A breathable membrane is a material, which in service conditions, is sufficiently fine to prevent the ingress of liquid water but permeable enough to allow the transfer of water vapour to adequately limit the risk of condensation in roofs (BBA, 2004). These high performance materials can provide a barrier against wind driven rain and snow, whilst allowing water vapour in the loft space to pass through to the air space beneath the external tiled finish, where it can disperse into the atmosphere (Essah et al., 2009; HTF, 2006). 
Table 1. Reports of problems where BRMs have been fitted into existing bat roosts

\begin{tabular}{|c|c|c|c|c|c|c|c|c|}
\hline Year & Area & $\begin{array}{l}\text { Membrane } \\
\text { type }^{1}\end{array}$ & $\begin{array}{l}\text { No. Dead } \\
\text { bats }\end{array}$ & $\begin{array}{l}\text { Bats seen } \\
\text { struggling? }\end{array}$ & $\begin{array}{l}\text { Fluffing } \\
\text { visible? }\end{array}$ & $\begin{array}{l}\text { Damage to } \\
\text { functional layer? }\end{array}$ & Species Affected & Comments \\
\hline 2004 & Dorset, UK & BRM & 2 & No & Yes & Yes & Serotine bats & BRM in a poor state. Completely worn through in areas \\
\hline 2007 & Cumbria, UK & $\begin{array}{l}\text { BRM } \\
\text { (DuPont) }\end{array}$ & 12 & No & Yes & Yes & Pipistrelle sp. & Membrane had been fitted 7 years previous, very stained with strong smell of urine \\
\hline 2007 & Devon, UK & Bitumen & 2 & No & N/A & N/A & Serotine bats & $\begin{array}{l}\text { Bitumen felt in older part of building, in extremely poor state due to age, hessian fibres hanging } \\
\text { loose }\end{array}$ \\
\hline 2007 & Devon, UK & $\begin{array}{l}\text { BRM } \\
\text { (DuPont) }\end{array}$ & $10^{*}$ & No & Yes & Yes & Serotine bats & Membrane was worn through in places \\
\hline 2010 & Cumbria, UK & $\begin{array}{l}\text { BRM } \\
\text { (DuPont) }\end{array}$ & 0 & No & No & Yes & Pipistrelle sp. & $\begin{array}{l}\text { Membrane only visible from internal roof, staining had seeped through large sections of mem- } \\
\text { brane }\end{array}$ \\
\hline 2010 & Cumbria, UK & $\begin{array}{l}\text { BRM } \\
\text { (Klober) }\end{array}$ & 2 & No & Yes & Yes & Pipistrelle sp. & Parts of the membrane were completely worn through \\
\hline 2010 & Cornwall, UK & $\begin{array}{l}\text { BRM } \\
\text { (Proctor) }\end{array}$ & 0 & Yes & Yes & Yes & Brown long-eared bats & Fluffing visible throughout the internal roof space along the ridge \\
\hline 2010 & Cardiff, UK & BRM & 0 & Yes & Yes & Yes & $\begin{array}{l}\text { Brown long-eared bats } \\
\text { Lesser horseshoe bats }\end{array}$ & Membrane had been left exposed, but BLE were seen struggling during visit \\
\hline 2010 & Norfolk, UK & $\begin{array}{l}\text { BRM } \\
\text { (Klober) }\end{array}$ & 5 & No & Yes & Yes & Pipistrelle sp. & $\begin{array}{l}\text { Membrane had been fitted 5years previous, roost contained } 140 \text { bats, membrane had large areas of } \\
\text { fluffing }\end{array}$ \\
\hline 2011 & Devon, UK & $\begin{array}{l}\text { BRM } \\
\text { (Proctor) }\end{array}$ & 1 & Yes & Yes & No & $\begin{array}{l}\text { Brown long-eared bats } \\
\text { Lesser horseshoe bats } \\
\text { Greater horseshoe bats }\end{array}$ & $\begin{array}{l}\text { Small roost (12 each of BLE and LHS and } 3 \text { GHS) - however widespread fluffing throughout } \\
\text { roost. } \\
\text { membrane in situ since } 2000 \text { - Membrane now being removed due to issues with bats }\end{array}$ \\
\hline 2011 & Somerset, UK & BRM & 0 & Yes & Yes & Yes & Brown long-eared bats & Membrane had been in-situ for 18 months \\
\hline 2012 & Cornwall, UK & Bitumen & 2 & No & N/A & N/A & Noctule bats & $\begin{array}{l}\text { Largest known noctule roost in UK, with over } 300 \text { bats. Bitumen matrix exposed in areas which } \\
\text { has entangled bats }\end{array}$ \\
\hline 2012 & Cumbria, UK & $\begin{array}{l}\text { BRM } \\
\text { (Proctor) }\end{array}$ & 0 & Yes & Yes & Yes & Brown long-eared bats & Membrane had only been in situ for around 6 months - two groups of 15 bats \\
\hline 2012 & Cumbria, UK & $\begin{array}{l}\text { BRM } \\
\text { (Klober) }\end{array}$ & 0 & Yes & Yes & Yes & Brown long-eared bats & Membrane had only been in situ for around 6 months - one group of 5 adult bats with young \\
\hline 2007 & Dublin, Ireland & BRM & $20^{*}$ & No & Yes & Yes & Serotine bats & Parts of the membrane were completely worn through \\
\hline 2012 & Oxfordshire. UK & $\begin{array}{l}\text { BRM } \\
\text { (DuPont) }\end{array}$ & 30 & No & Yes & Yes & Pipistrelle sp. & Dead bats found between BRM and tiles, not visible from internal roof space \\
\hline 2012 & $\begin{array}{l}\text { North Slovakia, } \\
\text { EU }\end{array}$ & BRM & 1 & No & Yes & Yes & Mouse-eared bats & ME bats are larger than species in the UK, membranes was completely destroyed and delaminated \\
\hline 2013 & $\begin{array}{l}\text { North Yorkshire, } \\
\text { UK }\end{array}$ & BRM & $104 *$ & No & Yes & Yes & Pipistrelle sp. & Parts of the membrane were completely worn through \\
\hline
\end{tabular}

1 Membrane manufacturer given if known for reference only

* Minimum number of bats dead through entanglement. Only whole corpses counted 


\subsubsection{Manufacture processes}

BRMs typically comprise spun-bonded polypropylene (SBPP) filaments or a polypropylene and polyethylene mix, laminated either side of a functional vapour permeable layer (BBA, 2004). The basic spun-bonding system involves sheets of synthetic fibres, extruded onto a moving conveyor belt as a randomly orientated web (Wilson, 2007). The spun-bond sheet is then bonded with further non-woven webs or other products to produce a laminate, the layers of which are often then fixed using point bonding (Bhat, 2007).

Within the UK BRMs are produced using four main manufacture methods, all of which encompass spun-bond polypropylene in some way. However, manufacturers often have their own methods of bonding the membrane layers or creating the channels that allow the membrane to breathe.

\subsubsection{Flash Spun-bonded}

Flash spinning uses a modified spun-bond method where an explosive reaction produces a 3D network of continuous fibres. The high level of molecular orientation gives an increased level of strength (Bhat, 2007). This method is used solely by DuPont ${ }^{\mathrm{TM}}$ to produce Tyvek ${ }^{\circledR}$ products. The flash spun-bond layer has filaments so closely interwoven that it is impervious to liquid water but vapour permeable and so acts as a functional layer (Weber, 2011); this is then protected by a layer of spun-bonded polypropylene (SBBP) on the external sides. This acts to protect the functional layer during fitting.

\subsubsection{Microporous Film}

Used throughout Europe since 1997/8 (Weber, 2011), these BRMs constitute $70 \%$ of those available in the UK. They are manufactured by laminating a fine microporous functional layer between two protective layers of SBBP.

\subsubsection{Monolithic Film}

Similar in construction to the microporous membranes, however, the difference lies with the functional layer. The monolithic film is not microporous; instead water vapour is actively transported through the entirety of the membrane layer via absorption and evaporation.

\subsubsection{SMS Technology}

SMS (Spun-bond, melt-blown, spun-bond) technology uses yet another method to produce the functional vapour permeable layer. High velocity air, used during extrusion, produces micro-fibres (Dahiya et al., 2004) which increases the porosity of the membrane to water vapour.

Between 1988 and 2003 the production of nonwovens for roofing applications, more than trebled (Massenaux, 2003), and this figure has continued to rise. In the UK alone there are over 60 brands of non-woven BRM available on the market.

\section{Bats in the UK}

In the UK, there are 17 species of bats which are considered residents (known to be breeding), all of which are small in size ( ranging from 4-30g in weight) (Dietz et al., 2009) and insectivorous. Though small in size they are long-lived, have low fecundity, high survivorship, relatively long periods of infant dependency and advanced age at sexual maturity when compared to other small mammals (Findley, 1993).

Insectivorous bats living in temperate climates such as the British Isles may experience food supply variations during summer months and are therefore forced into a narrow 'window of opportunity' with regards to rearing young (Ransome, 1998). With litter size restricted by prolonged gestation, infant dependency and a limited season of food availability, most female bats give birth to only a single offspring in any year (Findley, 1993). Bat populations are therefore often slow to recover from incidents that threaten their ability to survive or breed and are particularly vulnerable to anthropogenic and environmental changes.

Bats require undisturbed places in which to roost. A roost can be defined as 'any place a bat uses for shelter, protection or rest' (Mitchell-Jones, 2004) and they are critical resources for bats as they provide safety and the correct environmental conditions required by the bat at that time. Disturbance to roosts may have a major impact on the fitness and survival of bats (Campbell et al., 2010; Entwistle et al., 1997; Jenkins et al., 1998). This is why bats and their roost sites are heavily protected throughout the EU by both European e.g. Council Directive 92/43/EEC on the conservation of natural habitats and of wild fauna and flora and domestic legislation e.g. in England and Wales the Wildlife and Countryside Act (1981) (as amended) and The Conservation of Habitats and Species Regulations (2010), which transposes the Directive.

\subsection{Roosting Habits}

Bats spend a significant proportion of their lives within their roost (Lewis, 1995). During the summer months this can be up to 20 hours per day (Jenkins et al., 1998). Roosts are therefore one of the most important features of a bat's environment.

In order to meet their thermoregulatory and energetic needs, most bat species will utilise several different types of roost during an annual cycle. These may include spring gathering roosts, maternity roosts, mating roosts, night roosts and hibernation sites (Dietz et al., 2009). Loss of roost sites is considered to be one of the main threats to bats, as their colonial habits make them particularly vulnerable to catastrophes, whether natural or man-made (Mitchell-Jones et al., 1989).

Before the rapid urbanisation of the last century, bats mainly roosted in hollow trees, rock crevices or caves (Stebbings, 1988). This loss of natural roosts, due to human environmental impact, has increased the relative importance of man-made structures for the provision of bat roosts. As a 
result many roosts in buildings are now crucial for the survival of the bats relying on them (Agnelli et al., 2010).

\subsection{How Bats Use Buildings}

All species of British bat will make use of buildings to varying degrees (Stebbings, 1988), either through loss of natural roost sites or because man-made sites offer preferable conditions (Entwistle et al., 1997; Lausen and Barclay, 2006). Some species in the UK have become so well adapted to man-made structures they are found in buildings more often than natural roosts; including the common pipistrelle (Pipistrellus pipistrellus), the soprano pipistrelle (Pipistrellus pygmaeus), serotine bats (Eptesicus serotinus), brown long-eared bats (Plecotus auritus), grey long-eared bats (Plecotus autriacus) and Natterer's bat (Myotis nattereri) (Dietz et al., 2009; Hutson, 1993).

Bats will make use of a wide range of buildings, though more species and greater numbers have been recorded in older buildings (Briggs, 2004; Simon et al., 2004; Williams, 2010), probably due to the increased roosting opportunities created through building degradation. This preference for older buildings can mean bats often occupy properties where remedial work is required. Maintenance activities in buildings can prove catastrophic for bats, as seen historically with the use of remedial timber treatments which resulted in the death of large numbers of bats throughout Europe (Mitchell-Jones et al., 1989). The loss of summer roosts through renovation work, particularly within maternity roost assemblages, may pose a great threat to building reliant bat species (Harbusch and Racey, 2006).

\subsection{Importance of Roofs as Roosts}

Buildings provide a wide spectrum of roosting opportunities, but for the purpose of this review we will consider only those located in the roof space. The roof offers many sites both external and internal, for a number of different bat species (Figure 2). Externally, principal sites are under tiles, within the eaves or squeezed between the primary roof covering and the underlay (Agnelli et al., 2010; Hutson, 1993; Richardson, 2002). The narrow gap between the underlay and exterior roof covering is sufficient for a wide range of British bat species.

The internal roof space provides roosting opportunities along the ridge, around the gable ends (Hutson, 1993), in crevices behind fixtures (Simon et al., 2004), in close contact with timbers (Mitchell-Jones et al., 1989) or directly against the roofing underlay.
How bats enter the roof space may also vary between species; most will crawl in to the roost via small gaps, whereas horseshoe bats require flying access (Schofield, 2008). The tunnel below the ridge tiles is used by many bat species, either as a roost or as access to other roost sites. Other favoured access points are at the end of the ridge or at junctions with chimneys, for example under raised flashing (Hutson, 1993). For those that access the roof via, or roost in crevices, the bats belly and back are often in direct contact with the building materials (Hutson, 1993).

\section{Incorporation of BRMS into Bat Roosts}

During the past century traditional roofing underlay such as bitumen felt has been considered a safe option for use within bat roosts, with only two known reports of problems occurring (Table 1). However, modern roofing methods favour non-woven materials such as BRMs and since their introduction into UK roof construction around 15 years ago, the production and use of non-woven materials has grown rapidly (Massenaux, 2003). Whilst it is believed that traditional felts will still be widely available (Garrand, 2008), the drive to meet stricter building regulations, economic reasons and ease of use, means the use of BRMs will continue to increase. By 2004 the building and roofing industries accounted for 12.5\% of the total nonwoven materials used in Europe (EDANA, 2004). Such statistics are important when considering bats often occupy buildings in need of remedial work. Renovation or changes of use, of old buildings, have often been overlooked for their importance in preserving bat colonies(Agnelli et al., 2010).Today where proposed developments will affect sites known to be used by bats, consideration needs to be given to the likely impact on the bat population. Even when planning permission is given, or no such consent is required, the wildlife legislation applies; bats and the places used for roosting are protected (Mitchell-Jones, 2004).

From an architectural and manufacturing perspective with regards to BRMs, as with all building components, building regulations require that such materials be fit for purpose (HTF, 2006) and with reports that both bats and BRMs may experience problems when the two interact, it is important to know how both bats and BRMs may be affected. In order to investigate potential problems it is first important to understand what happens when bats and BRMs come into contact. 


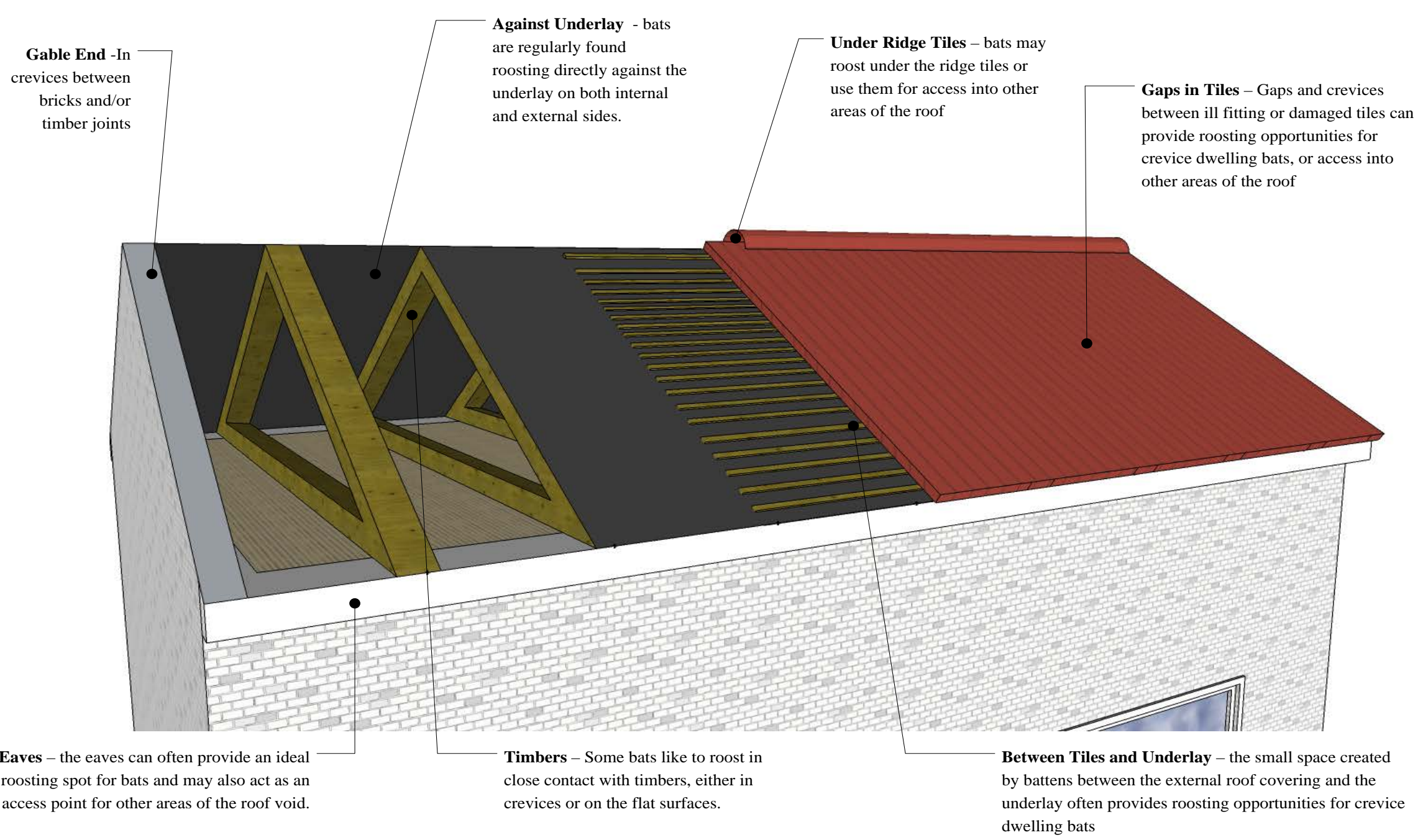

Fig.2. Areas where bats may be found roosting within a standard pitched roof in the UK 


\subsection{How Bats Roost Against BRMs}

Bats may roost in a variety of places within the roof space and on both sides of the underlay or BRM. For species that roost in the main void and those who roost in the crevice between the tiles and underlay, being able to grip onto the surface is essential. To facilitate roosting upon a wide range of surfaces, bats have long, keeled claws on their toes which are designed to grip suitable substrates (Cartmill, 1985). They also have toes which can be spread to provide grip at different angles and improve purchase (Dietz et al., 2009).

Most British bats are very active crawlers, with both fore and hind limbs employed in fast locomotion, scuttling, hanging from and crawling along roost surfaces (Orr, 1971). For bats roosting on the underside of the underlay, the feet support the main weight of the bat, but most UK species also use their thumb claws to improve grip. The claws found on bat species within the UK taper to an extremely sharp tip which interacts with the membrane surface at such a fine level that individual or clusters of filaments may be pulled loose.

As bats roost, their entire body is often in contact with the surface of the BRM. In order to keep their fur and wing membranes in good condition bats, like most mammals, secrete natural oils from glands over their body. Close contact with BRMs in the roof space may lead to the transfer of these oils from the bats fur along with contact of excrement produced within the roost.

\section{Reports of Problems}

Since 2004 there has been growing concern from bat conservationists over the suitability of BRMs for use in bat roosts. Recently these concerns have been substantiated with reports of 16 separate instances (Table 1) where problems, such as membrane fluffing, entanglement or membrane damage, had arisen following the fitting of BRMs into existing bat roosts. These reports highlighted problems in two main areas; entanglement and membrane longevity. However, concerns have also been raised that BRMs could alter the microclimatic regime of a roof void, which may lead to conditions for roosting becoming unsuitable.

\subsection{Entanglement}

This review was stimulated by reports of bat deaths following entanglement- caught up in the filaments and not able to free themselves - in the SBBP filaments pulled loose from the BRM.

The SBBP filaments produced during manufacture are extremely strong as they are designed to protect the functional layer during fitting, from environmental exposure and mechanical damage through movement. They are also extremely long, and form an entangled web, which along with additional bonding points hold the filaments in the BRM together. In order to test the mechanical strength of BRMs under standard conditions they are subjected to tear tests to determine tear strength (BSI, 2000). For a BRM to perform well in a tear test the filaments need to be strong and mobile, this allows them to reorient and straighten out. As a result rather than tear the SBPP filaments remain intact and continue to re-orientate and straighten as point bonds break.

Whilst industrial tests represent the stresses that BRMs may encounter within a normal roof space, they do not simulate the potential stresses the membrane may be exposed to in bat roosts. The problem with this is that neither test accounts for either the small scale of bats claws or the fact that they penetrate the SBPP fibres when gripping. This action may lead to bats grabbing the spun-bond fibres and teasing them apart. This then results in small clusters of fibres being pulled away from the main membrane which can be seen as a 'fluffing' on the surface of the BRM, which may pose an entanglement threat. Reports of bats found dead following entanglement are becoming increasingly common, as roosts where BRMs have been fitted are being re-visited. In some cases BRMs are showing signs of entanglement potential within months of the bats returning, after the BRM had been fitted. Figures 3 and 4 show 'fluffing' of two different membranes, both of which had been fitted in brown long-eared bat roosts only 6 months prior to the visits. In other scenarios BRMs are being removed from projects that were re-roofed up to 15 years ago and large numbers (between 12 and 104) of dead bats are being found tangled in filaments that have been pulled loose.

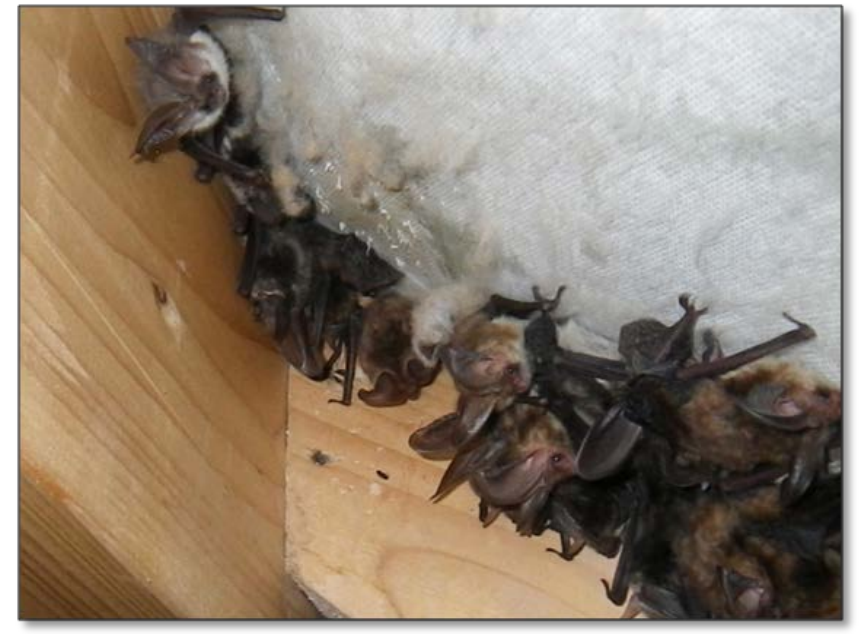

Fig.3. Picture of 'fluffing' on BRM six months after being fitted in a brown long-eared bat roost (Photo Credit - John Martin, 2012, Cumbria, UK) 


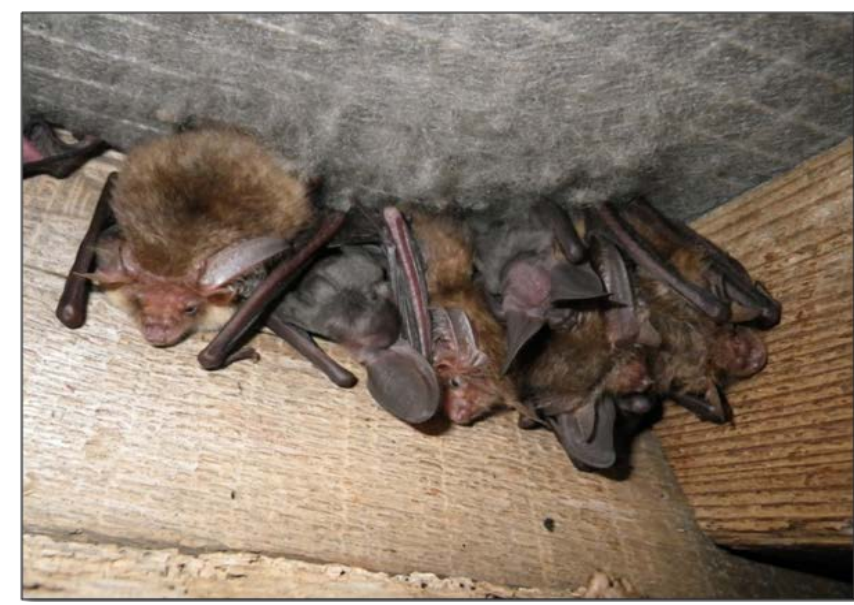

Fig.4. Picture of 'fluffing' on BRM six months after being fitted in a brown long-eared bat roost (Photo Credit - John Martin, 2012, Cumbria UK)

\subsubsection{Why bats die from entanglement}

Bats could die through entanglement because once the membrane has 'fluffed up' bats claws can become caught up in the filaments and it can be hard for bats to free themselves. Bats have very low body weights (Richardson, 2002) due to the constraints of flight; this means that bats that do become entangled, often do not have the force required to free themselves from any fibres that trap them (Figure 5). This could be a more worrying scenario for bats which roost between the external roof covering and the underlay, as they have the disadvantage of not being able to use their body weight or wing strength to break free.

In some species, the calls of distressed bats may attract other bats from within the roost to the area of danger, and with such behaviour recorded (Dietz et al., 2009) this problem has the potential not to just affect individuals but larger numbers within the roost (Fig. 6).

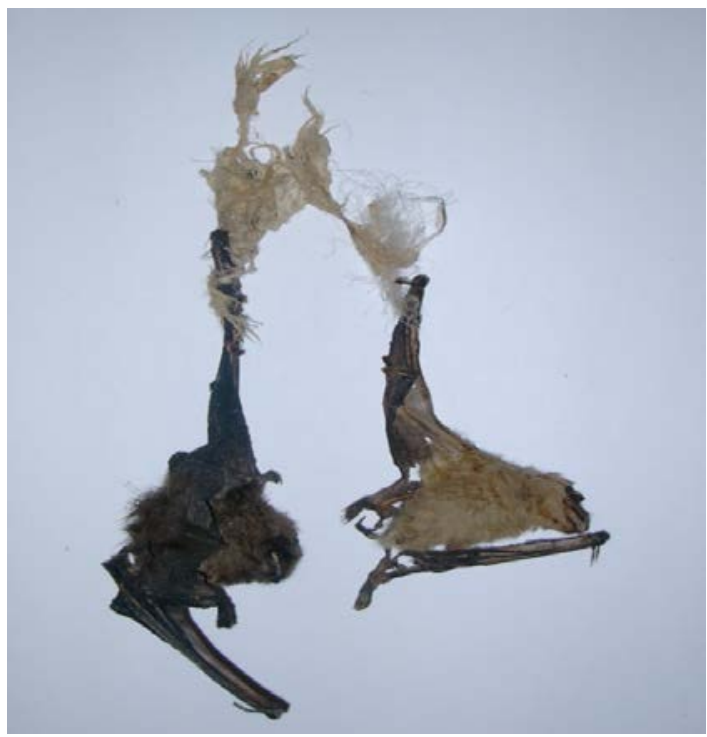

Fig.5. Two serotine bats found dead after becoming tangled in SBBP fibres pulled loose from a BRM (Photo Credit - Colin Morris, 2004, Dorset
UK)

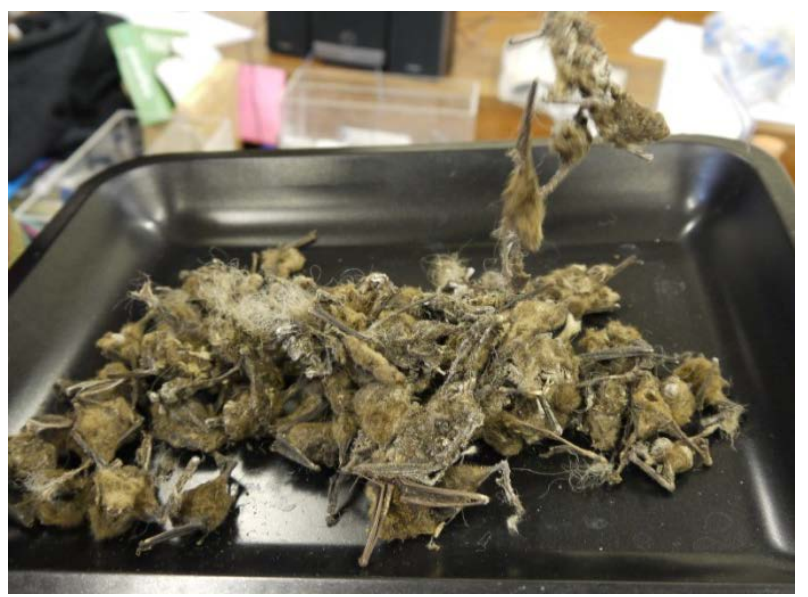

Fig.6. Large number of pipistrelle bats (104 were counted in total) found dead trapped in a BRM (Photo Credit -Stacey Waring, 2013, North Yorkshire UK)

\subsection{Membrane Longevity}

When designing BRMs, manufacturers have to meet strict guidelines on durability and suitability for purpose. It is mostly during fitting and before project completion that BRMs are faced with their principal degradation factors, including extreme temperatures, solar radiation, water, wind (Lounis et al., 1999; Weber, 2011), roof traffic (Garrand, 2008) and environmental pollution (Marcellus and Kyle, 1997). To account for such concerns over product longevity, manufacturers aim to offer service life guarantees for the membranes, often following rigorous testing.

Previously it has been assumed that any further degradation would be due to inadequate design, poor maintenance and human activity. Yet no research has taken into account any deterioration related to bat use, including claw damage, contact with fur and natural oils and excrement absorption. In order for a membrane to be suitable for use within a bat roost it must not only be considered 'bat friendly' i.e. have minimal impact on bat populations, but also be able to stand up to use by bats, i.e. remain functional.

\subsubsection{How could bats reduce membrane functionality?}

The main two functions of a BRM are to allow water vapour to escape the roof void, thus reducing the risk of condensation and to act as a secondary barrier against inclement weather. When BRMs are placed in a roof where bats are known to roost, there is a high chance of the membrane coming into contact with substances not found in roof voids under other circumstances; including urine, faeces and natural oils. There is also the consistent abrasive action upon the BRM from the bats claws, which applies unanticipated forces to the membrane surfaces. Therefore, interactions between bats and BRMs have the potential to diminish the functionality of BRMs. Below we consider how breathability and water 
tightness may be compromised.

\subsubsection{Potential for reduction in Breathability}

In the vast majority of BRMs on the market the ability to 'breathe' is due to the presence of microscopic channels within the membrane (either via a microporous film or channels through the densely packed filaments), that allow water vapour to pass through the membrane. However, if these channels were to become blocked by substances such as natural oils or excrement they would cease to allow water vapour to pass through and would have a decreased level of functionality.

Bats are known to roost on both sides of the membrane and whilst faecal matter is unlikely to stick to the underside of BRMs (and is probably of little concern in the main roof void), it can build up in the batten void under the tiles (Fig. 7).

Due to an insectivorous diet bat faeces easily crumble into a fine powder and so can be distributed across the membrane surface. Furthermore, urine is also easily absorbed into BRMs and can be seen as staining in roof spaces where bats are roosting against BRMs (Fig. 8).

Bat urine consists of $70 \%$ urea (Paine, 1991), which can oxidise to form nitrates and then reduce to ammonia. In the presence of other atmospheric substances such as carbolic acid (which is found in a large range of building materials and everyday plastics), ammonium carbonate can form. This substance is not only corrosive but can encourage the settling of dust. Such nitrates are also hygroscopic in nature and they may also contribute to the formation of condensation on the membrane surface(Paine, 1991).

Finally, we need to consider if the natural oils (described in section 4.1) are transferred from bat fur onto the membrane surface, and whether this has an effect on membrane breathability. Such contamination of the membranes with liquid pollutants, dust from crumbled faeces and natural oils, has the potential to block the microscopic channels that facilitate the movement of water vapour through the membrane and effectively reduce functionality. This in turn could lead to an increased risk of condensation within the roof.

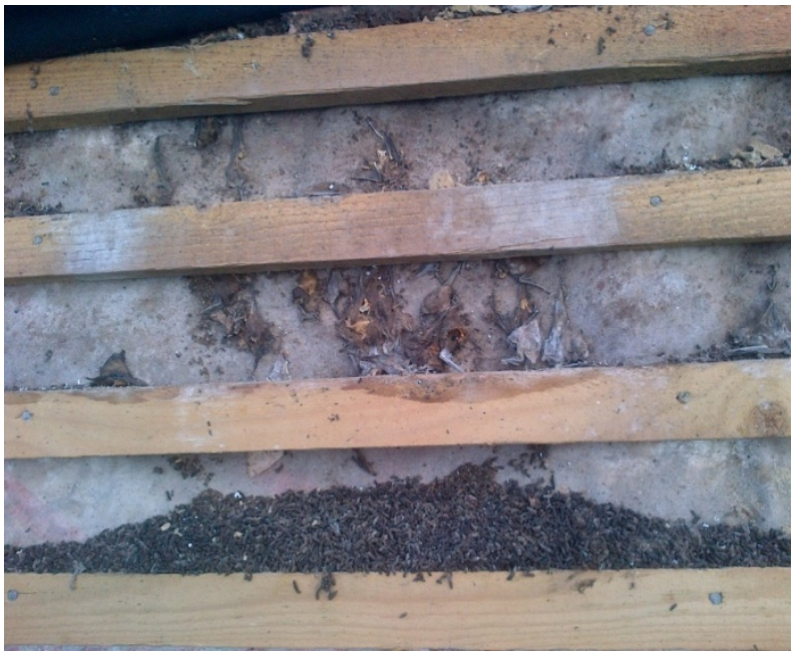

Fig.7. Faeces build-up between BRM and the roof tiles. Thirty bats were also found dead following entanglement in loose filaments (Photo Credit Rob Gray, 2012, Oxfordshire UK)

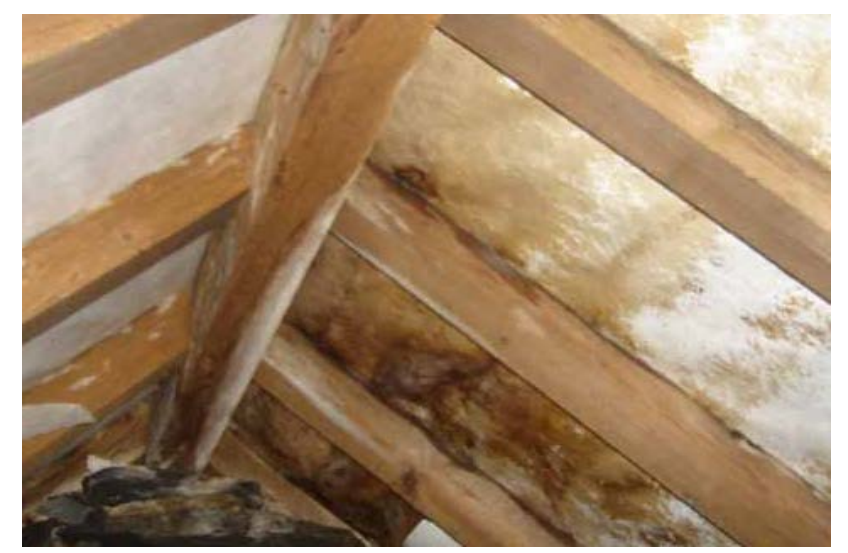

Fig.8. Staining of a BRM through absorption of excrement (Photo Credit - Shirley Martin, 2010, Cumbria UK)

\subsubsection{Potential for reduction in watertightness}

Bats spend the majority of their time in their roosts (see section 3.1), and often move around within the roost to adjust to environmental conditions or to warm up before leaving the roost to feed in the evening. This means that the BRM surface is often undergoing a high (and unaccounted for) level of abrasion. As the surface is abraded, SBPP filaments are teased loose and so provide less protection to the functional layer of the membrane, which often provides the watertight barrier. Most membranes available in the UK are less than $1 \mathrm{~mm}$ thick and with the average bat species claws ranging from 1-3mm in length (Dietz et al., 2009), there is the potential that whilst roosting against the membranes bats will puncture the membranes with their claws.

A majority of BRMs (94\%) inspected by the researcher following reports of problems, showed damage to the functional layer and in some cases the membrane had been worn away completely (Figures 9 and 10). In cases such as this, where the membrane has become damaged, this could allow any liquid water present under the tiles to enter the roof space, effectively reducing or removing the watertight properties of the membrane. 


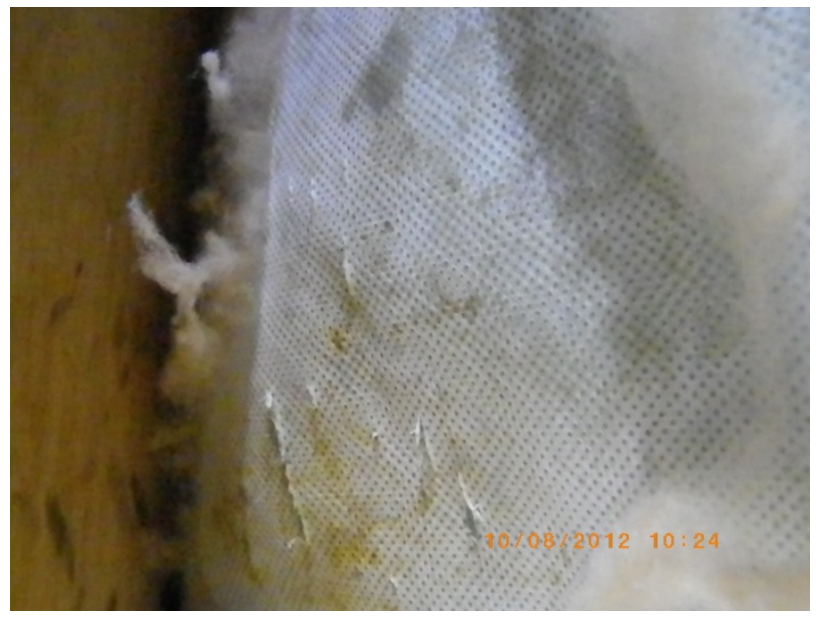

Fig.9. BRM showing damage to the functional layer six months after fitting in a bat roost (Photo Credit -John Martin, 2012, Cumbria UK)

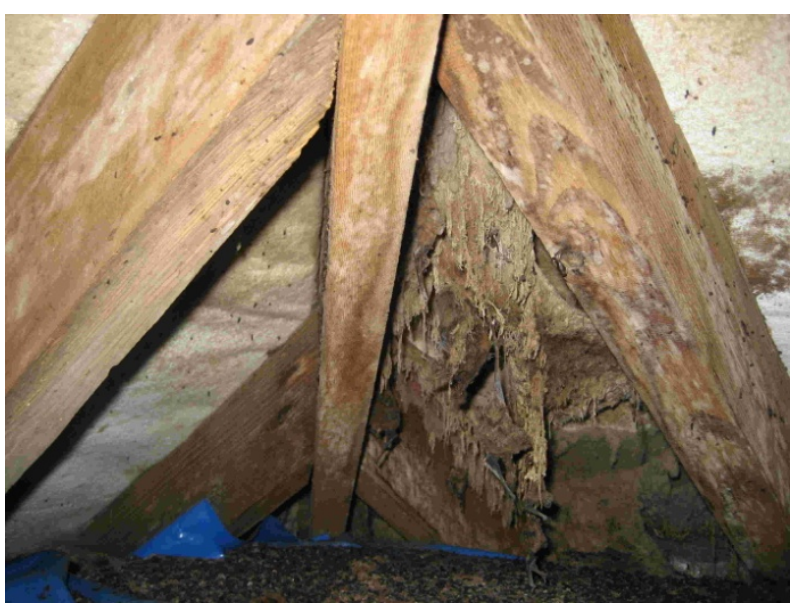

Fig.10. Damaged membrane in which 20 dead bats were found entangled (Photo Credit - Paul Scott, 2007, Dublin, Ireland)

\section{Current Solutions}

At present when faced with the question 'which BRMs are suitable for use within a bat roost?' we can make no recommendations. In the past bitumen felt has been used with very few reports of problems and so current knowledge would suggest using a bituminous felt with ventilation to err on the side of caution. However, this is often a hard option to sell as many people involved in the building industry feel this is in conflict with strict energy efficiency guidelines. BRMs are often the preferred option in the roofing industry as they are easier to use and fit and can in some cases prove a cheaper alternative, compared to traditional felt. Another reason for their popularity is that before 2011 BRMs did not require the incorporation of ventilation in the UK.

One solution, often put forward by bat workers, to help reduce the chance of bats becoming entangled in loose membrane fibres, is to put traditional bitumen felt up against the membrane to provide a safe surface for bats to roost against. However, there are concerns within the BRM industry over this practice (Payne, 2011; Weber, 2011), because when a BRM is laid over a material which has a high resistance to water vapour, it does not reduce this resistance. In situations where BRMs are laid over a material of high resistance, such as rigid boarding, counter battens may be deemed necessary, to prevent any moisture building up between the materials (Stirling, 2002). If this is not taken into account, condensation may still form in the roof space and be held against the BRM, which in turn could cause deterioration of one or more of the membranes components.

\section{The Need for Further Research}

This emerging problem brings two very different disciplines together and shows that in order to create a truly sustainable built environment many factors must be considered.

Wildlife legislation has made bats among the best protected mammals in Europe, however, aspects of bat conservation are often directly affected by individuals and commercial sectors whose primary concern is not biodiversity (Haysom et al., 2010). Given the high roost fidelity evident in bats (Entwistle, 1994) and the importance of specific roost characteristics, changes to existing roosts may have detrimental effects for bat populations (Entwistle et al., 1997). Therefore new building regulations and the introduction of new materials and practices, may substantially reduce the availability of roosting opportunities in both new and current buildings (Haysom et al., 2010).

Where proposed developments will affect sites known to be used by bats, consideration needs to be given to the likely impact on the population. Planning Policy Statement 9 on Biodiversity and Geological conservation(Office of the Deputy Prime Minister, 2005) (now replaced by the National Planning Policy Framework) (National Planning Policy Framework, 2012) stated that 'the presence of a protected species is a material consideration when a local planning authority is considering a development proposal, which if carried out, would be likely to result in harm to the species or its habitat'. Even when planning permission is given, or no such consent is required, the wildlife legislation applies; bats and the places used for roosting are protected (Mitchell-Jones, 2004). It is therefore important that any threat posed to bats and their roost sites within buildings is researched and where appropriate, mitigated.

However, it is also imperative that the industrial application of BRMs in bat roosts is researched. Most companies, in order to improve their product, reduce complaints and to increase reliability, now guarantee their product against degradation and failure. Some of these warranties offer up to 30years guaranteed service life. As there is no current consideration for the conditions a BRM is subjected to within a bat roost, it is very important to determine whether or not use 
by bats can cause early deterioration of the membranes and therefore lead to shortened service lives of roofs. In this scenario, it would be appropriate to identify or develop membranes that are suitable for use where bats are present.

These concerns have important implications for both bat conservation and the BRM industry. It is essential that further research into this area is carried out and clear mitigation guidelines for the use of BRMs in bat roosts developed.

\section{Acknowledgments}

We would like to thank the Bat Conservation Trust, Natural England, Countryside Council for Wales (CCW) and EPSRC for helping to fund the project. Also many thanks to Dr Karen Haysom, Dr Carol Williams and Prof. George Jeronimidis for their help in reviewing this paper, and all those who provided advice and support through the projects steering committee and donated images and samples for further research.

\section{References}

Agnelli, P., Russo, D., Martinoli, A., 2010. Guidelines for the conservation of bats in buildings and the resolution of related conflicts, Quaderni di Conservazione della Natura. Ministero dell'Ambiente e della Tutela del Territorio e del Mare, Ministero per i Beni e le Attivita Culturali, Gruppo Italiano Ricera Chirotteri e Universita degli Studi dell'Insubria, Italy.

Bartonička, T., Řehák, Z., 2007. Influence of the microclimate of bat boxes on their occupation by the soprano pipistrelle Pipistrellus pygmaeus: possible cause of roost switching. Acta Chiropterologica 9, 517-526.

BBA, 2004. Breathable roof tile underlays in cold roofs. BBA Article. 06.

Bhat, G., 2007. Polymer-laid web formation, in: Russell, S. (Ed.), Handbook of Nonwovens. CRC Press; Woodhead Pub. Ltd., Boca Raton Fla. ;Cambridge, pp. 143-200.

Briggs, P., 2004. Effect of barn conversion on bat roost sites in Hertfordshire, England. Mammalia 68, 353-364.

British Standards Institute, 2000. BS 747:2000 Reinforced bitumen sheets for roofing. Specification, GBM48 (Construction In General). BSI.

BSI, 2000. BS EN 12310-2:2000 Flexible sheets for waterproofing. Determination of resistance to tearing. Plastic and rubber sheets for roof waterproofing, GBM49 (Building Materials \& Components).

Campbell, S., Coulson, G., Lumsden, L.F., 2010. Divergent Microclimates in Artificial and Natural Roosts of the Large-Footed Myotis (Myotis macropus). Acta Chiropterologica 12, 173-185.

Cartmill, 1985. Climbing, in: Hildebrand, M., Bramble, D.M., Liem, K.F., Wake, D.B. (Eds.), Functional Vertebrate Morphology. Harvard University Press, pp. 73-88.

Sanders, C. 2006. Modelling condensation and airflow in pitched roofs (No. Information Paper Information Paper 5/06). BRE.

Council Directive on the Conservation of Natural Habitats and of Wild Fauna and Flora, 1992.

CRC, 2001. Construction Research Communications -Remedying condensation in domestic pitched tiled roofs., Good repair guides. BRE.

Dahiya, A., Kamath, M.G., Hegde, R.R., 2004. Melt Blown Technology [WWW Document]. URL

http://www.engr.utk.edu/mse/Textiles/Melt\%20Blown\%20Technology. htm (accessed 9.5.11).

Dietz, C., Helversen, O. von, Nill, D., 2009. Bats of Britain, Europe and Northwest Africa. A. \& C. Black, London.

EDANA, 2004. Nonwoven Statistics.
Entwistle, A.C., 1994. Roost ecology of the brown long-eared bat (Plecotus auritus, Linnaeus 1758) in north-east Scotland. Phd Thesis, University of Aberdeen

Entwistle, A.C., Racey, P.A., Speakman, J.R., 1997. Roost Selection by the Brown Long-Eared Bat Plecotus auritus. J. Appl. Ecol. 34, 399-408.

Essah, E.A., Sanders, C., Baker, P., Kalagasidis, A.S., 2009. Condensation and moisture transport in cold roofs: effects of roof underlay. Build. Res. Inf. 37, 117-128.

Findley, J.S., 1993. Bats: a community perspective. CUP Archive.

Garrand, C., 2008. Roofing: technical review. RIBA, London.

Goss, R., 2007. Goss's roofing ready reckoner: metric dimensions for timber roofs of any span and pitch., 4th ed. / Chris N. Mindham. ed. Blackwell, Oxford; Malden MA.

Harbusch, C., Racey, P.A., 2006. The sessile serotine: the influence of roost temperature on philopatry and reproductive phenology of Eptesicus serotinus (Schreber, 1774) (Mammalia: Chiroptera). Acta Chiropterologica 8, 213-229.

Harrison, H.W., Trotman, P. M, Saunders, G. K, 2009. Roofs and roofing: performance, diagnosis, maintenance, repair and the avoidance of defects., BRE Building Elements Series. BRE Press.

Haysom, K.A., Jones, G., Merrett, D., Racey, P.A., 2010. Bats, in: Maclean, N. (Ed.), Silent Summer: the State of Wildlife in Britain and Ireland. Cambridge University Press, Cambridge; New York, pp. 259-280.

HM Government, 2008. Strategy for Sustainable Construction.

HTF, 2006. The use of low water resistance (type LR) underlays in "cold" pitched roof systems for dwellings (for construction professionals) (Leaflet No. Note 6), Technical Guidance. Hertfordshire Building Control Technical Forum.

Hutson, A., 1993. Bats in houses. Bat Conservation Trust, London.

JenkinsS, E.V., Laine, T., Morgan, S.E., Cole, K.R., Speakman, J.R., 1998. Roost selection in the pipistrelle bat, Pipistrellus pipistrellus (Chiroptera: Vespertilionidae), in northeast Scotland. Anim. Behav. 56, 909-917.

Lausen, C.L., Barclay, R.M.R., 2006. Benefits of Living in a Building: Big Brown Bats (Eptesicus fuscus) in Rocks versus Buildings. J. Mammal. 87, 362-370.

Lewis, S.E., 1995. Roost Fidelity of Bats: A Review. J. Mammal. 76, 481-496.

Lounis, Z., Lacasse, M.A., Vanier, D.J., Kyle, B.R., 1999. Towards standardizationof service life prediction of roofing membranes, in: Wallace, T.J., Rossiter, W.J., Materials, A.C.D.-8 on R., Waterproofing, and Bituminous (Eds.), Roofing Research and Standards Development. ASTM International, p. 1349.

Marcellus, R., Kyle, B., 1997. Theoretical limit states functions for low slope roofing systems, in: Canadian Society for Civil Engineering Annual Conference.

Massenaux, G., 2003. Introduction to nonwovens, in: Albrecht, W., Fuchs, H., Kittelmann, W. (Eds.), Nonwoven Fabrics: Raw Maerials, Applications, Characteristics and Testing Processes. Wiley-VCH.

Mitchell-Jones, A.J., 2004. Bat Mitigation Guidelines. English Nature.

Mitchell-Jones, A.J., Cooke, A.S., Boyd, I.L., Stebbings, R.E., 1989. Bats and remedial timber treatment chemicals a review. Mammal Rev. 19, 93-110.

Moussy, C., 2011. Selection of old stone buildings as summer day roost by the brown long-eared bat Plecotus auritus. Acta Chiropterologica 13, 101-111.

National Planning Policy Framework, 2012.

Office of the Deputy Prime Minister, 2005. Planning Policy Statement 9: Biodiversity and Geological Conservation.

Orr, R., 1971. Development pre-natal and post-natal, in: Wimsatt, W.A. (Ed.), Biology of Bats: V. 1, Biology of Bats. Academic Press Inc, pp. 217-230.

Paine, S., 1991. The effects of bat excreta on wall paintings. Courtauld Institue of Art \& Getty Conservation Institue.

Payne, J., 2011. Breathable Roofing membranes. 
Ransome, R., 1998. The impact of maternity roost conditions on populations of greater horseshoe bats (Project report No. 292), English Nature Research Reports. English Nature.

Richardson, P., 2002. Bats. Natural History Museum, London.

Sanders, C., 2006. Airtightness of ceilings: energy loss and condensation risk, Information papers. Building Research Establishment, Watford [England].

Schofield, H., 2008. The lesser horseshoe bat: conservation handbook. Vincent Wildlife Trust, Ledbury.

Simon, M., Huttenbugel, S., Smit-Viergutz, J., 2004. Ecology and conservation of bats in villages and towns: results of the scientific part of the testing \& development project "Creating a network of roost sites for bat species inhabiting human settlements, [Bindeeinheit]. ed, Schriftenreihe fur Landschaftspflege und Naturschutz. BfN, Bonn - Bad Godesberg.

Stebbings, R.E., 1988. The conservation of European bats. Christopher Helm.

Stirling, C., 2002. Ventilated and Unventilated Cold Pitched Roofs, Good Buiding Guide. IHS BRE.

The Conservation of Habitats and Species Regulations 2010 [WWW Document], n.d. URL

http://www.legislation.gov.uk/uksi/2010/490/contents/made (accessed 11.7.12).

Waring, S., Essah, E.A., Gunnell, K., Bonser, R., 2012. Breathable Roofing Membranes and Bats: Interactions, Outcomes and Predictions, in: Amoeda, R., Mateus, R., Braganca, L., Pinheiro, C. (Eds.), BSA 2012 Proceedings of the 1st International Conference on Building Sustainability Assessment. Presented at the BSA 2012, Green Lines Institute, Porto, Portugal, pp. 175-184.

Weber, C., 2011. Tyvek ${ }^{\circledR}$ longevity vs. other product technologies.

Wildlife and Countryside Act 1981 [WWW Document], n.d. URL http://www.legislation.gov.uk/ukpga/1981/69 (accessed 11.7.12).

Williams, A., 2008. Interstitital condensation: The core prolem of relative humidity, in: Shortcuts- Book 1: Structure and Fabric, At-a-glance Guides for Building Designers. NBS / RIBA Enterprises, London.

Williams, C., 2010. Biodiversity for low and zero carbon buildings : a technical guide for new build. RIBA Pub., London.

Wilson, A., 2007. Development of the nonwovens industry, in: Russell, S.

(Ed.), Handbook of Nonwovens. CRC Press; Woodhead Pub. Ltd., Boca Raton Fla. ; Cambridge, pp. 1-15. 